\title{
Economic impact of juvenile idiopathic arthritis and familial Mediterranean fever
}

\author{
Ilker Kemal Yucel · Emire Seyahi • \\ Ozgur Kasapcopur • Nil Arisoy
}

Received: 31 October 2010/Accepted: 13 March 2011/Published online: 3 April 2011

(c) The Author(s) 2011. This article is published with open access at Springerlink.com

\begin{abstract}
The aim of the study was to determine the economical impact of juvenile idiopathic arthritis (JIA) and familial Mediterranean fever (FMF) in Turkey. A total of 100 patients $(69 \mathrm{~F} / 31 \mathrm{M})$ with JIA and 100 with FMF (68 $\mathrm{F} / 32 \mathrm{~F})$ who were consecutively seen in the outpatient clinic of the pediatric rheumatology department at Cerrahpasa Medical School between August 2008 and January 2009 were studied. Cost data were collected through a questionnaire filled out by the parents. The mean age (JIA: $11 \pm 5$ years; FMF: $12 \pm 4$ years) and mean disease duration (JIA: $5 \pm 3$ years; FMF: $4 \pm 3$ years) of the patients were similar. JIA patients were assigned to 5 subtypes (polyarticular: $n=45$, oligoarticular: $n=30$, systemic onset: $n=13$, psoriatic: $n=6$, and enthesopathy-related JIA: $n=6$ ). Forty-nine percent of the patients with JIA were treated with anti-TNF drugs and $61 \%$ with DMARDs. All patients with FMF were using colchicine. The total annual cost of JIA ( $€ 3,994 \pm 4,101)$ was considerably higher than that of FMF $(€ 162 \pm 77)$ $(P<0.001)$. Medication fee was the major determinant of total costs in both diseases constituting $85 \%$ in JIA and $39 \%$ in FMF. Among the subtypes of JIA, total annual costs were the highest among patients with polyarticular
\end{abstract}

I. K. Yucel · O. Kasapcopur · N. Arisoy

Department of Pediatric Rheumatology,

Cerrahpasa Medical School, Istanbul University,

Istanbul, Turkey

E. Seyahi

Department of Rheumatology, Cerrahpasa Medical School, Istanbul University, Istanbul, Turkey

O. Kasapcopur $(\square)$

Atakoy 1. Kisim D-43/8, 34158 Istanbul, Turkey

e-mail: ozgurkc@istanbul.edu.tr;

ozgurkasapcopur@hotmail.com type (€6,045 $\pm 4,078)$. Medications especially anti-TNF drugs were the major contributor among all determinants of costs in JIA. The low costs of health care system and prominent changes in the health care policies for the last 5 years in Turkey might have played role in our findings.

Keywords Juvenile idiopathic arthritis · Familial Mediterranean fever - Cost of illness study - Direct costs . Indirect costs - Etanercept · Anti-TNF agents · Turkey

Juvenile idiopathic arthritis (JIA) is the most common rheumatic disease in childhood [1]. It is a debilitating chronic disease with considerable morbidity and mortality. Multidisciplinary management of the patients with frequent hospital visits accompanied by various medical and physical treatments results in considerable economic burden on the health care system. Widespread use of anti-TNF agents causes further increments in the costs. Moreover, economic burden of the disease may extend into the adulthood [2]. Despite all these, studies investigating the economic impact of JIA are limited in number [2-7] and few $[4,5,7]$ sought the cost of biological therapies.

Familial Mediterranean fever (FMF), on the other hand, is an autoinflammatory disease common in eastern Mediterranean populations [8]. It is characterized by self-limited episodes of fever, serosal and synovial inflammation such as peritonitis, pleuritis, and arthritis, as well as myalgia and erysipelas-like erythema [8, 9]. Amyloidosis leading to chronic renal failure is its most severe complication, developing in 10-15\% of patients [8]. FMF can be associated with necrotizing vasculitis, ankylosing spondylitis, and chronic inflammatory bowel diseases. Apart from these associations, it has no apparent morbidity and causes no disability and usually treated with colchicine alone. To our 
knowledge, no cost of illness study in patients with FMF has been done before.

In this study, we aimed to estimate the economic burden of patients with JIA attending a pediatric tertiary referral center in Istanbul, Turkey and as the control group we used patients with FMF.

\section{Patients and methods}

We studied consecutive patients with JIA and FMF who were seen in the pediatric rheumatology outpatient clinic of Cerrahpasa Medical Faculty at the University of Istanbul between August 2008 and January 2009. Patients with JIA were diagnosed according to ILAR criteria [10] and assigned to a subtype. However, due to small number in each group we had to accumulate the patients into 5 main clinical types. Patients with FMF fulfilled the Livneh diagnostic criteria [11]. Only patients with at least 1 year of diagnosis were included in the study.

Disease characteristics, laboratory data, and drug information were obtained form the patient's charts. Functional limitation of patients with JIA was assessed by using Childhood HAQ (CHAQ) score at the time of the study entry. The parent (if the child $<8$ years old) or the child (if the child $\geq 8$ years old) completed a CHAQ validated for use in the Turkish population [12].

Patients with JIA are seen routinely every 3 months in the outpatient unit; however, visits can be more frequent if necessary. In each visit, laboratory tests (ESR, whole blood count, liver tests and urine dipstick test) were done. Physiotherapy is also given as part of the management and decision as to whether splints/devices are necessary is taken in the same unit. Patients with FMF, however, are seen twice a year in the outpatient clinic. Laboratory tests that are requested in each visit are whole blood count, ESR, and urine dipstick test.

\section{Socioeconomic evaluation}

Data on demographic, educational, and employment status of parents were obtained by questionnaire. Five variables were used to measure socioeconomical status: education, occupation, monthly family income, wealth score, and sum of the household members. Wealth score was calculated by summing the items/goods or proprieties found in the individual or household's possession. The items were telephone, mobile telephone, washing machine, dishwasher, personal computer, house, summer house, and car. Each item was scored as 1 point, giving the range of WS between 0 and 8 .

\section{Resource use and cost assessment}

The information on expenses directly or indirectly related to the disease within the preceding 3 months was collected by interviewing parents with the help of a structured questionnaire. Twelve-month costs were estimated multiplying these data by 4 . All costs were converted into euro $(€)$ using the purchasing power parity value of Turkey as of January 2009 ( $1 €=2.15$ YTL).

The unit price of each service (outpatient visits and blood, biochemistry, and radiological tests) was determined according to the price list set by the Cerrahpasa Medical Faculty.

Other outpatient visits such as physiotherapy, ophthalmology, endocrinology, or emergency and private practice visits are priced according to price set by each relevant facility. Physician visits not related to JIA or FMF are excluded from the analyses. Hospitalization costs were estimated for the 12 months prior to study entry. Information related to type and dose of the medications was obtained from patient's charts. The costs of the drugs were obtained from the price list set by the Turkish Ministry of Health. Costs of generic drugs were used.

Medications used in the treatment of patients with JIA were ibuprofen, indomethacin, prednisolone, methotrexate (MTX), sulphasalazine (SAZ), cyclosporine (CSA), etanercept (Enbrel), infliximab (Remicade), gastroprotective agents, calcium, vitamin $\mathrm{D}$, and biphosphonate. Patients with FMF were treated with colchicine.

Costs of splinting, devices, and aids were estimated considering those used for the preceding 12 months.

\section{Non-health care costs}

Non-health care costs covered 3 months and included disease-related expenditure like transport and lodging and domestic help.

\section{Indirect costs}

Indirect costs were evaluated by considering parents' time away from paid work due to children's disease (JIA and FMF). An estimate of the loss of productivity was obtained by multiplying the cumulative number of work days lost over the preceding 3 months by 4 and by the individual daily wage of the parent.

\section{Social security system in Turkey}

The study was done after the unification of the social security system in Turkey by law on March 2006 [13-15]. 
This system collected social security institutions of civil servants, contractual paid workers, agricultural paid workers, self-employers, and agricultural self-employers into one to offer equal actuarial rights and obligations. By this law, all children under 18 years old who are not considered as insurance holders or are not holders of voluntary insurance are under the coverage of social security institution [16]. All health expenditures including hospitalization, laboratory tests, investigations, hospital visits, and medications are fully reimbursed.

Ethic committee of the Cerrahpasa Medical Faculty approved the study, and oral informed consent was taken from the parents before each interview.

\section{Statistical analysis}

Continuous variables with a normal distribution were expressed as means \pm SDs and others with non-normal distribution as medians and interquartile ranges [IQR]. Categorical variables were compared using the chi-square test or Fisher's exact tests. Comparisons of continuous variables were made by using Student's $t$ tests and one-way ANOVA followed by Tukey HSD test. Demographic, clinical, and socioeconomical variables that are associated with cost were determined first by univariate analysis than tested with multiple logistic regression analyses.
Independent variables that were used in these analyses were gender, age, disease duration, wealth score, CHAQ score, ANA and RF positivity, and JIA subgroups. Total annual cost was dichotomized into high and low cost as upper and lower of the median value of $€ 2,345$ for JIA and used in the multiple regression tests. All statistical analyses were carried out using statistical software (SPSS, version 13.0 for Windows; SPSS, Chicago, IL).

\section{Results}

Patient demographics, clinical characteristics, and socioeconomic status

We studied 100 (31 M/69 F; mean age: $10.5 \pm 4.6$ years) patients with JIA and 100 (32 M/68 F; mean age: $11.5 \pm 4.1$ years) patients with FMF. Table 1 shows demographic characteristics and socioeconomic status of the study participants (Table 1). Patients with JIA were more likely to have longer disease duration and less likely to live in Istanbul compared to patients with FMF. Parental education, occupation status, and social security types did not differ among those with JIA and FMF. Fathers of 2 patients with JIA and one with FMF had deceased. Patients with JIA had significantly lower wealth score and higher total count of household members compared to patients
Table 1 Demographic characteristics and socioeconomic status of patients

${ }^{\text {a }}$ Fathers of 2 patients with JIA and one with FMF had deceased

\begin{tabular}{lllr}
\hline & JIA $(n=100)$ & FMF $(n=100)$ & $P$ \\
\hline Female, $n(\%)$ & $69(69)$ & $68(68)$ & 0.879 \\
Age, mean \pm SD, years & $10.5 \pm 4.6$ & $11.5 \pm 4.1$ & 0.082 \\
Disease duration, mean \pm SD, years & $5.3 \pm 3.4$ & $4.4 \pm 3.4$ & 0.056 \\
Istanbul, $n(\%)$ & $77(77)$ & $89(89)$ & 0.024 \\
Parental employement status ${ }^{\mathrm{a}}, n(\%)$ & & & \\
Professional (like lawyer, doctor, & $6(3)$ & $4(2)$ & 0.781 \\
teacher, architect...) or director & & & \\
Office worker & $15(8)$ & $21(11)$ & \\
Unskilled worker & $78(39)$ & $70(35)$ & $15(8)$ \\
Retired & $9(15)$ & $5(3)$ & 0.90 \\
Unemployed & $3(1)$ & $84(42)$ & \\
Housewife & $87(44)$ & & \\
Parental education ${ }^{\mathrm{a}}, n(\%)$ & & $12(6)$ & \\
None & $13(7)$ & $140(70)$ & 0.479 \\
Primary school & $138(69)$ & $28(14)$ & 0.011 \\
High school & $29(15)$ & $20(10)$ & \\
University & $18(9)$ & $98(98)$ & \\
Social security, $n(\%)$ & $100(100)$ & $4.3 \pm 1.0$ & \\
Total count of household members, mean \pm SD & $5.0 \pm 1.4$ & $672 \pm 310$ & \\
Monthly income per family in $€$, mean \pm SD & $644 \pm 243$ & \\
Wealth score, mean \pm SD & $4.8 \pm 1.6$ & \\
\hline
\end{tabular}


with FMF, indicating lower socioeconomical status in JIA patients. The mean monthly income per family was similar between two study groups (Table 1).

ESR and counts of white blood cells (WBC) and platelets (PLT) were significantly higher among patients with JIA compared to those with FMF, indicating a higher inflammatory state among patients with JIA (ESR: $32.0 \pm 22.1$ vs. $21.1 \pm 14.1 \mathrm{~mm} / \mathrm{h}, \quad P<0.001$; WBC: $9,672 \pm 3,649$ vs. $7,983 \pm 2,859, \quad P<0.001 ; \quad$ PLT: $379.150 \pm 124.729$ vs. $298.020 \pm 83.412, P<0.001$, for JIA vs. FMF, respectively). However, hematocrite level was similar between the study groups $(36.4 \pm 3.4 \%$ vs. $36.8 \pm 3.2 \%, P=0.434)$.

The patients with JIA were divided into 5 clinical subgroups as shown in Table 2. Polyarthritis patients $(n=45)$ were in the majority followed by oligoarthritis ( $n=30)$, systemic $(n=13)$, psoriatic arthritis (PsA) $(n=6)$, and enthesitis-related arthritis (ERA) patients $(n=6)$. Except patients with ERA, patients with JIA were more likely to be women (Table 2). Patients with polyarthritis type and those with ERA were significantly older compared to the rest of the group. Disease duration was significantly longer among patients with polyarticular JIA compared to those with oligoarthritis. CHAQ scores did not differ between the subgroups of JIA (Table 2) and similarly, there was no significant difference between the subgroups of JIA with regard to ESR and whole blood counts (data not shown). By definition, the frequency of uveitis and positivity for ANA, RF, and HLA-B27 were significantly different between the subgroups of JIA (Table 2).

\section{Resource consumption}

As seen in Table 3, use of health care services per 3 months such as outpatient visits and biochemical and radiological tests was significantly more common among patients with JIA compared to patients with FMF. None of the parents had needed domestic help and care for the patients.

Table 2 Clinical characteristics of patients with juvenile idiopathic arthritis (JIA) according to subgroups

\begin{tabular}{|c|c|c|c|c|c|c|}
\hline & $\begin{array}{l}\text { Polyarthritis } \\
(n=45)\end{array}$ & $\begin{array}{l}\text { Oligoarthritis } \\
(n=30)\end{array}$ & $\begin{array}{l}\text { Systemic } \\
\text { arthritis } \\
(n=13)\end{array}$ & $\begin{array}{l}\text { Psoriatic } \\
\text { arthritis } \\
(n=6)\end{array}$ & $\begin{array}{l}\text { Enthesitis-related } \\
(n=6)\end{array}$ & $P$ \\
\hline Female, $n(\%)$ & $31(69)$ & $26(87)$ & $8(62)$ & $4(67)$ & 0 & $0.001^{\mathrm{a}, \mathrm{b}, \mathrm{c}, \mathrm{d}}$ \\
\hline Age, mean $\pm S D$, years & $12.3 \pm 4.4$ & $8.0 \pm 3.2$ & $8.5 \pm 5.3$ & $8.8 \pm 3.1$ & $14.2 \pm 3.0$ & $<0.001^{\mathrm{b}, \mathrm{c}, \mathrm{e}, \mathrm{f}}$ \\
\hline Disease duration, mean $\pm \mathrm{SD}$, years & $6.6 \pm 3.7$ & $3.8 \pm 2.3$ & $5.3 \pm 3.6$ & $5.1 \pm 3.4$ & $4.2 \pm 2.6$ & $0.01^{\mathrm{e}}$ \\
\hline $\mathrm{CHAQ}$, mean $\pm \mathrm{SD}$ & $0.30 \pm 0.50$ & $0.10 \pm 0.21$ & $0.16 \pm 0.35$ & $0.26 \pm 0.61$ & $0.23 \pm 0.46$ & 0.352 \\
\hline ANA $(+), n(\%)$ & $11(24)$ & $22(73)$ & $2(15)$ & $2(33)$ & 0 & $<0.001^{\mathrm{a}, \mathrm{b}, \mathrm{c}, \mathrm{d}}$ \\
\hline Uveitis (+), $n(\%)$ & 0 & $4(13)$ & 0 & 0 & 0 & 0.045 \\
\hline $\mathrm{RF}(+), n(\%)$ & $11(24)$ & $1(3)$ & $3(23)$ & $2(33)$ & 0 & 0.077 \\
\hline HLA B $27(+), n(\%)$ & 0 & 0 & 0 & 0 & $6(100)$ & $<0.001^{\mathrm{a}, \mathrm{b}, \mathrm{c}, \mathrm{c}}$ \\
\hline
\end{tabular}

${ }^{a}$ Enthesitis-related versus Polyarthritis; ${ }^{\mathrm{b}}$ Enthesitis-related versus oligoarthritis; ${ }^{\mathrm{c}}$ Enthesitis-related versus systemic arthritis; ${ }^{\mathrm{d}}$ Enthesitisrelated versus psoriatic arthritis; ${ }^{\mathrm{e}}$ Polyarthritis versus oligoarthritis; ${ }^{\mathrm{f}}$ Polyarthritis versus systemic arthritis

Table 3 Use of health care services and parental work day loss per 3 months

JIA Juvenile idiopathic arthritis, FMF Familial Mediterranean fever

\begin{tabular}{llll}
\hline & JIA, $n=100$ & FMF, $n=100$ & $P$ \\
\hline Outpatient visits, mean \pm SD & $2.9 \pm 1.0$ & $1.0 \pm 0.4$ & $<0.001$ \\
Biochemical tests, mean \pm SD & $5.9 \pm 0.8$ & $4.3 \pm 0.4$ & $<0.001$ \\
Radiological tests, $n(\%)$ & $24(24)$ & $5(5)$ & $<0.001$ \\
Physiotherapy, $n(\%)$ & $36(36)$ & 0 & $<0.001$ \\
Splints/braces, $n(\%)$ & $7(7)$ & 0 & 0.007 \\
Hospitalization, $n(\%)$ & $5(5)$ & $2(2)$ & 0.445 \\
Duration of hospitalization, mean \pm SD, days & $12.8 \pm 12.9$ & $5.5 \pm 6.4$ & 0.496 \\
$n$ who had underwent surgical operation, $n(\%)$ & 1 & 1 & 1.0 \\
Duration of hospitalization for surgery, days & 1 & 2 & 1.0 \\
$n$ of parents with work day loss, $n(\%)$ & $24(24)$ & $10(10)$ & 0.008 \\
Work days lost among parents, mean \pm SD, days & $2.75 \pm 3.03$ & $1.10 \pm 0.32$ & 0.014 \\
\hline
\end{tabular}


Parental work day loss

Parents who had work day loss and mean lost workdays due to the child's disease during a period of 3 months were significantly higher among patients with JIA compared to those with FMF (Table 3).

\section{Medications}

A total of $86(86 \%)$ patients with JIA used DMARDs (MTX, CSA and SAZ) and or anti-TNF agents along with corticosteroids and NSAIDs. Prednisolone (58\%), MTX (58\%), and etanercept (47\%) were the most frequently used drugs, followed by calcium tablets $(27 \%)$, gastroprotective agents (22\%), NSAIDs (12\%), CSA (4\%), infliximab (2\%), and SAZ (2\%). The remaining $14 \%$ were off treatment. The mean dose of MTX was $14.3 \pm 6.5 \mathrm{mg} /$ week and that of prednisolone was $8.1 \pm 6.7 \mathrm{mg} /$ day. The etanercept dose was $25 \mathrm{mg}$ once a week in 25 patients, twice a week in 11 others, $20 \mathrm{mg}$ per week in 5 , and $15 \mathrm{mg}$ per week in the 6 remaining patients.

When subgroups of JIA were analyzed separately, it was seen that etanercept was most commonly used by polyarthritis group (73\%) followed by PsA (50\%), ERA (33\%), systemic arthritis (23\%), and oligoarthritis (20\%) $(P<0.001)$. There were only two patients with JIA who were treated with infliximab (polyarthritis: 1 and oligoarthritis: 1). SAZ was used only by patients with ERA $(2 / 6)$. The use of other medications did not differ significantly between the subgroups. All FMF patients were using colchicine $(100 \%)$ and very few NSAIDs $(8 \%)$.

\section{Mean annual total costs and its components (Table 4)}

The mean annual total cost for the JIA cohort was estimated to be $€ 3,994 \pm 4,101$. The mean direct costs were
$98 \%$ of the total costs. Almost $85 \%$ of the total costs were incurred by the drugs ( $€ 3,381 \pm 3,881), 76 \%$ being just by anti-TNF agents $(€ 2,959 \pm 3,483)$. All other health care costs including outpatient visits $(1.4 \%)$, biochemical tests $(5.4 \%)$, radiological investigations $(0.3 \%)$, devices $(0.3 \%)$, physiotherapy $(0.5 \%)$, hospitalization $(0.6 \%)$, and surgeries $(0.06 \%)$ accounted for only $8 \%$ of the total costs. Transportation and lodging expenses made $4.7 \%$ of the total costs.

The mean annual total cost for FMF was calculated as $162 \pm 77 €$. As in JIA, the mean direct costs were $98 \%$ of the total costs and medications were the largest contributor to total costs $(39 \%)$ in the FMF cohort. Biochemical/ radiological tests $(32 \%)$, transportation and lodging $(13 \%)$, outpatient visits (9\%), hospitalization and surgery $(5 \%)$, and lost wages $(2 \%)$ were other contributors to the total costs in FMF. The mean annual total costs and almost all components of the total cost were found to be significantly lower in FMF compared to the JIA cohort (Table 4).

In each subtype of JIA, the largest contributor to the total costs was still the costs of medications, especially that of anti-TNF drugs. Among all subtypes, polyarthritis type had the highest total $(6,045 \pm 4,078 €)$ and anti-TNF drug costs $(4,770 \pm 3,514 €)$ followed by (in descending order) ERA (total costs: $4,828 \pm 6,228 €$, anti-TNF drugs: $2,625 \pm 4,393 €$ ), PsA (total: 3,219 $\pm 3,091 €$, anti-TNF drugs: $2,450 \pm 2,711 €$ ), oligoarthritis (total: $1,857 \pm$ $2,836 €$, anti-TNF drugs: $1,239 \pm 2,547 €)$, and systemic arthritis $(1,795 \pm 2,269 €$, anti-TNF drugs: $1,050 \pm$ 2,056€).

Total costs of those who were treated with anti-TNF drugs $(n=49)$ were estimated as $€ 7,530 \pm 2,984$, whereas that of those who were treated without anti-TNFs $(n=51)$ were calculated as $595 \pm 846 €$. While drug costs made $90 \%$ of the total costs in the anti-TNF group, transportation and lodging expenses (35\%) made the major contribution
Table 4 Mean annual costs and its components for patients with JIA and FMF (€)

$J I A$ Juvenile idiopathic arthritis, FMF Familial Mediterranean fever

\begin{tabular}{lcrr}
\hline & JIA $(n=100)$ & FMF $(n=100)$ & \multicolumn{1}{c}{$P$} \\
\hline Direct costs & $3,913 \pm 4,024$ & $159 \pm 76$ & $<0.001$ \\
Outpatient clinic visits & $55 \pm 29$ & $15.3 \pm 4$ & $<0.001$ \\
Biochemical tests & $216 \pm 119$ & $50 \pm 7$ & $<0.001$ \\
Radiological tests & $11 \pm 39$ & $2 \pm 15$ & 0.039 \\
Drugs & $3,381 \pm 3,881$ & $63 \pm 16$ & $<0.001$ \\
Anti-TNF agents & $2,959 \pm 3,483$ & 0 & $<0.001$ \\
Others & $422 \pm 760$ & $63 \pm 16$ & $<0.001$ \\
Devices & $12 \pm 52$ & 0 & 0.029 \\
Physiotherapy & $21 \pm 66$ & 0 & 0.001 \\
Hospitalization fees & $27 \pm 189$ & $4 \pm 33$ & 0.248 \\
Surgeries & $3 \pm 26$ & $4 \pm 40$ & 0.767 \\
Transportation and lodging expenses & $188 \pm 562$ & $21 \pm 39$ & 0.004 \\
Indirect costs & $81 \pm 257$ & $3 \pm 14$ & 0.003 \\
Total costs & $3,994 \pm 4,101$ & $162 \pm 77$ & $<0.001$ \\
\hline
\end{tabular}


Table 5 Variables associated with costs among patients with juvenile idiopathic arthritis (JIA)

\begin{tabular}{|c|c|c|c|}
\hline & $N$ & Mean \pm SD costs & $P$ \\
\hline \multicolumn{4}{|l|}{ Gender } \\
\hline Female & 69 & $3,721 \pm 3,699$ & \multirow[t]{2}{*}{0.325} \\
\hline Male & 31 & $4,589 \pm 4,893$ & \\
\hline \multicolumn{4}{|l|}{ Age } \\
\hline $2-9$ years & 42 & $1,926 \pm 2,533$ & \multirow[t]{2}{*}{$<0.001$} \\
\hline$\geq 10$ years & 58 & $5,490 \pm 4,378$ & \\
\hline \multicolumn{4}{|l|}{ Disease duration } \\
\hline $1-4$ years & 49 & $2,710 \pm 3,166$ & \multirow[t]{2}{*}{0.002} \\
\hline$\geq 5$ years & 51 & $5,226 \pm 4,529$ & \\
\hline \multicolumn{4}{|l|}{ Wealth score } \\
\hline $1-4$ & 43 & $2,549 \pm 2,875$ & \multirow[t]{2}{*}{0.001} \\
\hline $5-8$ & 57 & $5,083 \pm 4,552$ & \\
\hline \multicolumn{4}{|l|}{$A N A(+)$} \\
\hline Yes & 37 & $2,106 \pm 3,202$ & \multirow[t]{2}{*}{$<0.001$} \\
\hline No & 63 & $5,102 \pm 4,186$ & \\
\hline \multicolumn{4}{|l|}{$R F(+)$} \\
\hline Yes & 17 & $5,632 \pm 4,406$ & \multirow[t]{2}{*}{0.07} \\
\hline No & 83 & $3,658 \pm 3,981$ & \\
\hline \multicolumn{4}{|l|}{ CHAQ score } \\
\hline 0 & 54 & $2,915 \pm 3,913$ & \multirow[t]{2}{*}{0.004} \\
\hline$>0$ & 46 & $5,259 \pm 3,992$ & \\
\hline \multicolumn{4}{|l|}{ JIA subtype } \\
\hline Polyarticular type & 45 & $6,045 \pm 4,078$ & \multirow[t]{2}{*}{$<0.001$} \\
\hline All other types & 55 & $2,315 \pm 3,303$ & \\
\hline
\end{tabular}

to total costs followed by laboratory tests (31\%) and medications $(20 \%)$ in the other.

\section{Variables associated with high cost among patients with JIA (Table 5)}

As shown in Table 5, increased age, long disease duration, high wealth scores, high CHAQ scores, ANA negativity, and having a polyarthritis type of JIA were found to be associated with high total cost. In addition, JIA patients with RF (+) tended to have higher costs compared to those with RF (-). Multiple regression analyses showed that having a polyarthritis type of JIA (OR: 6.0, 95\% CI: 2.0-17.5, $P=0.001$ ), high CHAQ scores (OR: 3.5, 95\% CI: $1.2-10.3, P=023$ ), ANA negativity (OR: $3.3,95 \%$ CI: $1.0-10.2, P=0.04$ ), and high wealth scores (OR: $0.3,95 \%$ CI: $0.09-0.78, P=0.016$ ) were independently associated with high costs.

\section{Discussion}

In this study, the mean annual total cost of JIA in Turkey was estimated as $€ 3,994 \pm 4,101$. Cost of medications
(85\%), especially that of anti-TNF agents (76\%), made the largest contribution to the total cost. Among the subtypes of JIA, polyarthritis type had the highest cost. Meanwhile, the control group FMF was found to have a modest total annual cost $(€ 162 \pm 77)$.

The main results of the 5 JIA costing studies published within the last 6 years are summarized in Table $6[2,4-7]$. As there are great variances with regard to the health care systems, methodologies, patient characteristics, frequency of DMARDs and anti-TNF use, caution is required while comparing each other. Minden et al. in their first study assessed costs of JIA patients in the adulthood and found that $55 \%$ of the patients had still active disease after 17 years of disease onset [2]. The costs due to loss of productivity made $45 \%$ of the total costs in contrast to other studies including ours [4-7]. In their second study, Minden et al. assessed the costs in a younger JIA cohort [7]. They observed that health care costs accounted for $89 \%$ of total costs and medications contributed to half of this value [7]. The Finnish study evaluated especially the costs of etanercept addition to the prevailing drug therapy for a 1-year period [4]. While total median costs amounted to $\$ 7,732$ by the end of the year, the median direct costs per patient was increased by about $\$ 2,700$. However, authors observed a 50\% drop in the indirect costs [4]. Bernatsky et al. showed that direct costs for children with JIA ( $\$ 3002$ Canadian dollars) were higher than that for children without chronic disease ( $\$ 1,686$ Canadian dollars), particularly due to medication costs [5]. Thornthon et al. observed direct costs of JIA patients specifically in the first year of their diagnosis and found that the highest cost component was appointments with pediatric rheumatologists [6]. There is also another study that was done in the United States by Allaire et al. about two decades ago when biologics were not introduced and therapy with DMARDs was a new notion [3]. The mean annual direct cost per child was estimated as $\$ 7,905$, annual family costs averaged $\$ 1,524$ and medications contributed to only $7 \%$ of the health care costs [3].

Drugs are currently the main cost driver in rheumatoid arthritis $[17,18]$ and in most JIA costing studies including ours $[4,5,7]$ as shown in Table 6 . However, data about the use of DMARDs and biologics were not sufficient in these studies, despite the fact that most of them dated relatively to a recent period. Of the 5 studies, 3 did not determine DMARD use and 2 did not specify biologics use [2, 4, 6]. Moreover, of the remaining studies, in one, only about $1 / 3$ rd of the patients used DMARDs [5] and in 2, biological use was present in the minority of patients $[5,7]$. The rate of DMARD use (61\% vs. $68 \%$ ) was similar, however, that of biological use was substantially higher in our study compared to the recent German study (49\% vs. 6\%, respectively) [7]. This is most probably due to the great 
Table 6 Cost of illness studies in Juvenile Idiopathic Arthritis (JIA)

\begin{tabular}{|c|c|c|c|c|c|c|}
\hline $\begin{array}{l}\text { Author (ref. no), } \\
\text { publication date, } \\
\text { country }\end{array}$ & $\begin{array}{l}\text { Minden et al. [2] } \\
\text { 2004, Germany }\end{array}$ & $\begin{array}{l}\text { Haapasaari et al. [4] } \\
\text { 2004, } \\
\text { Finland }\end{array}$ & $\begin{array}{l}\text { Bernatsky et al. } \\
\text { [5] 2007, } \\
\text { Canada }\end{array}$ & $\begin{array}{l}\text { Thornton et al. [6] } \\
\text { 2008, England }\end{array}$ & $\begin{array}{l}\text { Minden et al. [7] } \\
\text { 2009, Germany }\end{array}$ & $\begin{array}{l}\text { Current study, } \\
\text { Turkey }\end{array}$ \\
\hline Years evaluated & 1998-2000 & 1999-2000 & 2005 & 2005 & 2003 & 2008-2009 \\
\hline$n$ & 215 & 31 & 155 & 297 & 369 & 100 \\
\hline Female & $116(54 \%)$ & Not specified & $108(70 \%)$ & $191(64 \%)$ & $263(71 \%)$ & $69(69 \%)$ \\
\hline Age, years & 23 & 10 & 10 & $8.2 \pm 4.3$ & 12 & $10.5 \pm 4.6$ \\
\hline $\begin{array}{l}\text { Disease duration, } \\
\text { years }\end{array}$ & 17 & 6 & 4.3 & 1 & 5 & $5.3 \pm 3.4$ \\
\hline DMARD use & Not specified & Not specified & $39 \%$ & Not specified & $242(68 \%)$ & $61(61 \%)$ \\
\hline $\begin{array}{l}\text { Biological drug } \\
\text { use }\end{array}$ & Not specified & $100 \%$ & $8(5 \%)$ & Not specified & $20(6 \%)$ & $49(49 \%)$ \\
\hline Costs & $\begin{array}{l}\text { Total cost: } \\
€ 3,471 \pm 9,032\end{array}$ & $\begin{array}{l}\text { Total cost: median } \\
\$ 7,732\end{array}$ & $\begin{array}{l}\text { Direct cost: } \\
\$ 3,002\end{array}$ & $\begin{array}{l}\text { Direct cost: } \\
€ 2,391 \pm 1,585\end{array}$ & $\begin{array}{l}\text { Total cost: } \\
€ 4,663 \pm 6,928\end{array}$ & $\begin{array}{l}\text { Total costs: } \\
€ 3,994 \pm 4,101\end{array}$ \\
\hline $\begin{array}{l}\text { Largest contributor } \\
\text { to cost }\end{array}$ & $\begin{array}{l}\text { Inpatient and } \\
\text { outpatient } \\
\text { health } \\
\text { care services }\end{array}$ & $\begin{array}{l}\text { Medications } \\
\text { (etanercept) }\end{array}$ & Medications & $\begin{array}{l}\text { Appointments for } \\
\text { pediatric } \\
\text { rheumatologists }\end{array}$ & Medications & Medications \\
\hline $\begin{array}{l}\text { Direct costs/total } \\
\text { costs }\end{array}$ & $55 \%$ & $95 \%$ & Not applicable & Not applicable & $94 \%$ & $98 \%$ \\
\hline
\end{tabular}

variance in the use of biologics according to the center's therapeutic approaches. Reimbursement by the health insurance systems may also play role. It is also to be noted that, although patients are included in a consecutive manner in the study, those who use anti-TNFs may tend to attend the outpatient clinic more frequently than those who do not use. Therefore, the current study may not represent the actual anti-TNF use in our center.

While medication was the major contributor to the health care cost, its share was almost $50 \%$ in most of the JIA costing studies [4, 5, 7]. However, in our study, this was $90 \%$. Similarly, contribution of medications was calculated as $78 \%$ in another cost of illness study done for Behçet's syndrome again in our institution [19]. In fact, when the costs for laboratory tests and devices were excluded, costs for inpatient and outpatient care, which also included physician visits, rheumatology consultations, physiotherapy, and nurse care, altogether made only $3 \%$ of the health care costs in JIA. This negligible share is the result of the low cost of health care system in Turkey. Prominent changes in the health care policies for the last 5 years as part of a health reform program helped more in the minimization of this share $[14,15]$. The reform program, which had aimed making health care available to a larger share of the population, caused much controversy. Decrease in the quality of the health care is one of its drawbacks.

Similar to what was reported in previous studies [2-7], we also showed that JIA causes considerable economic burden for the health care system in Turkey. However, with such a high rate of anti-TNF use at hand, one might have expected much increased total costs if the study had been done in Finland or Germany. This is, as mentioned earlier, due to low priced health care system in our country.

FMF is one of the most common disease in Turkey with a prevalence rate amounting to $0.9 \%[20,21]$. Our study is the first to assess socioeconomic status and economic impact of juvenile patients with FMF. While socioeconomic status was found to be more favorable, total costs were significantly lower in patients with FMF compared to those with JIA. Certain diseases such as asthma, coronary atherosclerosis, systemic lupus erythematosus, and $\mathrm{Be}$ hçet's syndrome have been reported to be more frequent in lower socioeconomic classes [22-25]. Furthermore, socioeconomic status and education may have impact on disease outcome [26]. On the other hand, this issue seems to be controversial for JIA, since one study from Denmark reported that children whose parents had a high income had a 2 times greater risk of developing JIA compared to age and sex matched controls [27]. It is also to be noted that, our study may not be conclusive, since parents of FMF patients may not represent general population in Turkey. Moreover, high wealth score was a predictor of high costs for JIA patients in our study, a fact supporting the Danish study.

This study has some limitations. Sample size of JIA subgroups was small and we did multiple comparisons; therefore, caution is needed in interpretation the results. Our findings are subject to recall bias because of the methodology used; similar to most cost of illness studies, our study was retrospective taking into account preceding 3 months. We did not evaluate missed school days of the 
patients. As part of out-of-pocket expenses we assessed only transportation and lodging expenses during the hospital visits and cost for any domestic help. Finally, since our study was done in Turkey and in a tertiary referral center, our results must not be generalized.

\section{Conclusions}

Our study is the first to estimate the direct and indirect costs for JIA and FMF in Turkey. The mean annual total cost of JIA was calculated as $€ 3,994 \pm 4,101$ and that of FMF as $€ 162 \pm 77$. More severe disease subtype and poor function incurred higher costs in JIA. Medications, particularly anti-TNF agents (76\%), were the major cost driver. Health care costs other than drugs were almost negligible. JIA imposes a substantial economic burden for the health care system in Turkey; however, considering the high rate of anti-TNF use, its burden is substantially lower compared to what was estimated in other countries.

Open Access This article is distributed under the terms of the Creative Commons Attribution Noncommercial License which permits any noncommercial use, distribution, and reproduction in any medium, provided the original author(s) and source are credited.

\section{References}

1. Minden K (2006) What are the costs of childhood rheumatic disease? Best Pract Res 20:223-240

2. Minden K, Niewerth M, Listing J et al (2004) Burden and cost of illness in patients with juvenile idiopathic arthritis. Ann Rheum Dis 63:836-842

3. Allaire SH, DeNardo BS, Ilona SS et al (1992) The economic impacts of juvenile rheumatoid arthritis. J Rheumatol 19:952-955

4. Haapasaari J, Kautiainen HJ, Isomaki HA, Hakala M (2004) Etanercept does not essentially increase the total costs of the treatment of refractory juvenile idiopathic arthritis. J Rheumatol 31:2286-2289

5. Bernatsky S, Duffy C, Malleson P et al (2007) Economic impact of juvenile idiopathic arthritis. Arthr Rheum 57:44-48

6. Thornton J, Lunt M, Ashcroft DM et al (2008) Costing juvenile idiopathic arthritis: examining patient based costs during the first year after diagnosis. Rheumatology 47:985-990

7. Minden K, Niewerth M, Listing J, Möbius D, Thon A, Ganser G, Ermisch-Omran B, Zink A (2009) The economic burden of juvenile idiopathic arthritis-results from the German paediatric rheumatologic database. Clin Exp Rheumatol 27:863-869

8. Tunca M, Akar S, Onen F, Ozdogan H, Kasapcopur O, Yalcinkaya F, Tutar E, Ozen S, Topaloglu R, Yilmaz E, Arici M, Bakkaloglu A, Besbas N, Akpolat T, Dinc A, Erken E, Turkish FMF Study Group (2005) Familial Mediterranean fever (FMF) in Turkey: results of a nationwide multicenter study. Medicine (Baltimore) 84:1-11

9. Ben-Chetrit E, Levy M (1998) FMF. Lancet 351:659-664

10. Petty RE, Southwood TR, Manners P et al (2004) International League of Associations for Rheumatology classification of juvenile idiopathic arthritis: second revision, Edmonton, 2001. J Rheumatol 31:390-392

11. Livneh A, Langevitz $\mathrm{P}$, Zemer D, Zaks N, Kees S, Lidar T, Migdal A, Padeh S, Pras M (1997) Criteria for the diagnosis of familial Mediterranean fever. Arthr Rheum 40:1879-1885

12. Ozdogan H, Ruperto N, Kasapçopur O, Bakkaloglu A, Arisoy N, Ozen S, Ugurlu U, Unsal E, Melikoglu M, Paediatric Rheumatology International Trials Organisation (2001) The Turkish version of the Childhood Health Assessment Questionnaire (CHAQ) and the Child Health Questionnaire (CHQ). Clin Exp Rheumatol 19(4 Suppl 23):S158-S162

13. http://www.sgk.gov.tr/wps/portal/en

14. http://en.wikipedia.org/wiki/Health_care_in_Turkey

15. http://www.euro.who.int/_data/assets/pdf_file/0007/96415/e79838. pdf

16. http://www.tuik.gov.tr

17. Huscher D, Merkesdal S, Thiele K, Zeidler H, Schneider M, Zink A, German Collaborative Arthritis Centres (2006) Cost of illness in rheumatoid arthritis, ankylosing spondylitis, psoriatic arthritis and systemic lupus erythematosus in Germany. Ann Rheum Dis 65:1175-1183

18. Jacobsson LT, Lindroth Y, Marsal L, Juran E, Bergström U, Kobelt G (2007) Rheumatoid arthritis: what does it cost and what factors are driving those costs? Results of a survey in a community-derived population in Malmö, Sweden. Scand J Rheumatol 36:179-183

19. Sut N, Seyahi E, Yurdakul S, Senocak M, Yazici H (2007) A cost analysis of Behcet's syndrome in Turkey. Rheumatology (Oxford) 46:678-682

20. Kisacik B, Yildirim B, Tasliyurt T, Ozyurt H, Ozyurt B, Yuce S, Kaya S, Ertenli I, Kiraz S (2009) Increased frequency of familial Mediterranean fever in northern Turkey: a population-based study. Rheumatol Int 29:1307-1309

21. Seyahi E, Tahir Turanli E, Mangan MS, Celikyapi G, Oktay V, Cevirgen D, Kuzuoglu D, Ozoglu S, Yazici H (2010) The prevalence of Behçet's syndrome, familial Mediterranean fever, HLA-B51 and MEFV gene mutations among ethnic Armenians living in Istanbul, Turkey. Clin Exp Rheumatol 28(4 Suppl 60):S67-S75

22. Ellison-Loschmann L, Sunyer J, Plana E, Pearce N, Zock JP, Jarvis D, Janson C, Antó JM, Kogevinas M, European Community Respiratory Health Survey (2007) Socioeconomic status, asthma and chronic bronchitis in a large community-based study. Eur Respir J 29:897-905

23. Falkstedt D, Lundberg I, Hemmingsson T (2010) Childhood socio-economic position and risk of coronary heart disease in middle age: a study of 49321 male conscripts. Eur J Public Health. 4 Nov 2010. [Epub ahead of print]

24. Sule S, Petri M (2006) Socioeconomic status in systemic lupus erythematosus. Lupus 15:720-723

25. Seyahi E, Ugurlu S, Seyahi N, Celik AF, Melikoglu M, Fresko I, Hamuryudan V, Yurdakul S, Yazici H (2004) A survey of socioeconomic status in Behçet's Syndrome. Clin Exp Rheumatol 22(Suppl 34):S88

26. Lee SJ, Kavanaugh A (2004) A need for greater reporting of socioeconomic status and race in clinical trials. Ann Rheum Dis 63:1700-1701

27. Nielsen HE, Dørup J, Herlin T, Larsen K, Nielsen S, Pedersen FK (1999) Epidemiology of juvenile chronic arthritis: risk dependent on sibship, parental income, and housing. J Rheumatol 26:1600-1605 